\title{
IFD Building Systems: a model simulating advantages of collaboration in the case of prefabrication in concrete
}

\author{
Frank De Troyer \\ KULeuven, Faculty of Engineering, \\ Department of Architecture, Urban Design and Physical Planning, \\ Kasteelpark Arenberg 1, B3001 Leuven, Belgium. \\ Frank.DeTroyer@asro.kuleuven.ac.be
}

\begin{abstract}
A characteristic of the building sector is that different actors (responsible for design, production, construction, use) are separated by markets. Those markets hide a lot of information. As an example the production costs of prefabricated concrete elements are considered. One market strategy of a production unit of those components can be to search for profitable contracts without providing information of the real cost structure. Another strategy can be to offer designer insight in how major design options affect cost and to come to a win-win situation: better quality for end users and higher profit margins for suppliers. A prerequisite for this is that within the production unit a clear insight in the costs exist. ABC (=Activity Based Costing) can be helpful.

Even more problematic is the integration of "cost-in-use" in the design process. Again the prerequisite is that cost information is available within the organisation in charge of running the real estate. If so the next step is that this information is made available for designers in such a way that the effect of major design decisions upon costs-in-use are transparent. An abstract model reducing the problem to the essence will prove that, even if modern information technology may improve the communication between actors, real collaboration requires transparent markets that can lead, provided good arrangements, to win-win situation for all actors involved.
\end{abstract}

KEYWORDS: Industrial, Flexible and Demountable (IFD), Building System, Activity Based Costing, Life cycle costing

\section{INTRODUCTION: the atomised construction sector and holistic optimisation}

A characteristic of the building sector is that different actors (responsible for design, production, construction, management and maintenance) are separated by markets. This separation is inherited from a period where the knowledge of building products available on the market (like bricks, cement tiles, ...) or of production technologies for purpose-made-products (like wooden stairs or windows) was shared between all partners. With the introduction of industrialisation in the building sector first the concept of mass production and secondly variation based on a catalogue was introduced. Since housing has a much deeper impact on our lives than most other consumer goods the issue of end-user-control was raised soon. A major concept, becoming even more important in view of sustainability, was John Habraken's proposal [Habraken] to consider two parts: the "support" and the "infill". This concept, however, does not solve the problem of the elaboration of "supports" in collaboration between designers, producers and users. In this text only the case of concrete elements will be elaborated. IFD is interpreted as the production of "supports" in an industrialised way allowing different uses in the future in combination with the production of components for the "infill". Also the "infill" should be produced in an industrialised way but on top of that allow dismantling and recombination. In this view there is no need for dismantling of the structure. This is, in view of sustainability the optimal situation: no dismantling costs, no waste, no recombination costs, no new inputs.

\section{MAJOR PARAMETERS EFFECTING COSTS OF CONCRETE COMPONENTS}

Cost information is, for most of the actors, a sensitive issue. Often markets are hiding the real cost structure for partners. As an example the production costs of prefabricated concrete elements is considered. One strategy of a production unit can be to search for profitable contracts without providing information on the real composition of 
the costs. Another strategy, however, can be to offer designers insight in how major design decisions affect costs. The aim of this is to come to a win-win situation: better quality for users (more adaptability, larger units, more variation, ...) and higher profit margins. A prerequisite of this is that within the production unit a clear insight in the costs exists. "Activity Based Costing" (=ABC) looks at the effect of certain characteristics upon the different steps of the production process and analyses how changes affect also "indirect" costs [Innes and Mitchell; Roztocki ]. In the case of concrete elements the steps are: preparing moulds, making the reinforcement, fixing the reinforcement in the moulds, mixing concrete, purring concrete, applying finishes, transport and storage at the production site, transport to the construction site and fixing elements on site. A detailed analysis [De Troyer] shows that in most steps a large fraction of the costs are the same as well for small elements as for large elements (Fig 1).

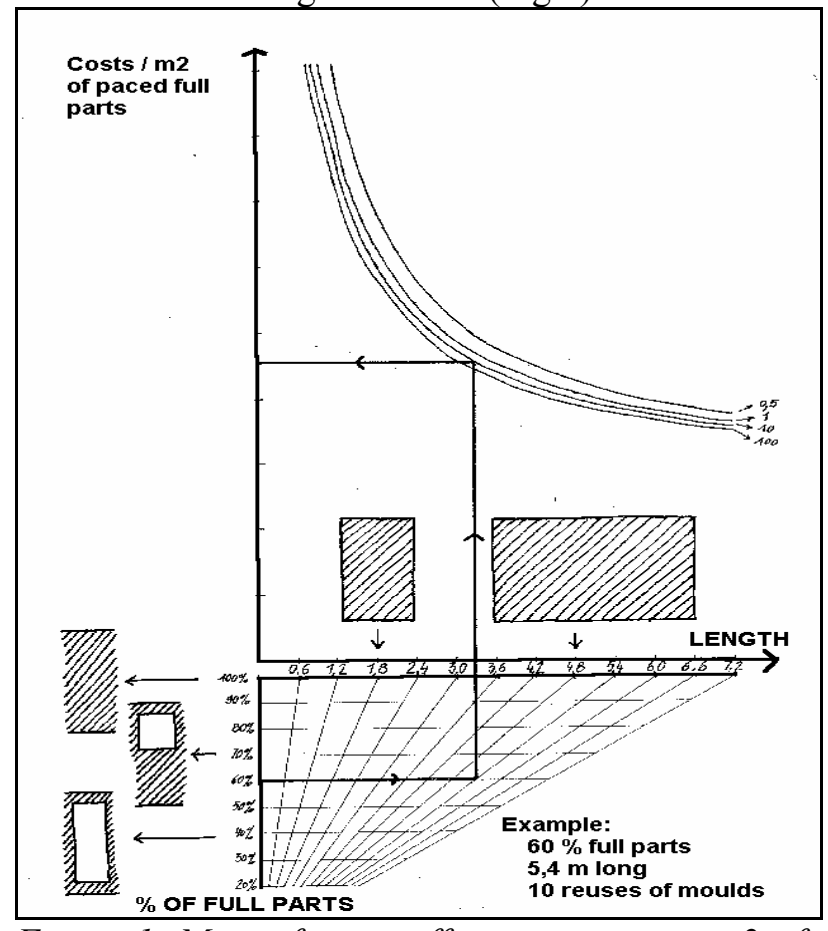

Figure 1. Major factors effecting costs per $m 2$ of wall panels

This is for instance the case for manipulations (once the lifting equipment is available), the elaboration and consultation of production drawings, operations in the production cycle. The consequence of that for wall elements is represented in a graphical way in figure 1: for a fixed height the price per $\mathrm{m}^{2}$ is decreasing in a hyperbolical way with the length. If those elements contain large openings the fixed costs per element have to be allocated to even less $\mathrm{m}^{2}$, so the price per $\mathrm{m}^{2}$ is higher.

If the manufacturer knows those effects upon costs, but only the price per $\mathrm{m}^{2}$ (based on an element with average length and percentage of openings) is communicated to the designer, the last cannot include this information in his evaluation of proposals. All projects whereby elements have on average characteristics right from point $\mathrm{A}$ can be produced at lower costs than the average.

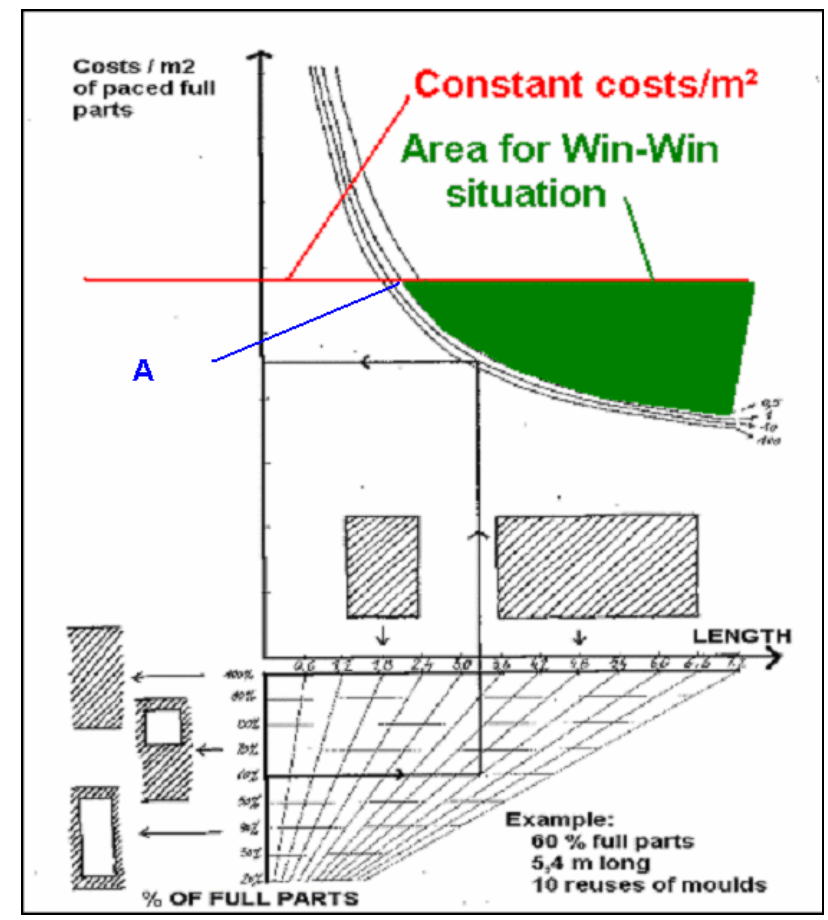

Figure 2. Different win-win situations.

The gray area represents possibilities for a win-win situation. For all points on the lower boundary of the gray area the production unit makes the same profit as in the "average" situation and the end user benefits from the saving; for the points on the top boundary the profit goes completely to the production unit. Depending on the market situation and different contractual arrangements an intermediate position will be taken. One can expect that the average length of concrete elements will be larger in the case of "supports". Also those elements will have fewer openings. In the present situation many small elements with a large fraction of openings are often produced (for toilets, bath rooms, circulation).

Designers, afraid that extra bending forces will increase costs, might reject the choice for "supports" with larger spans. In fact the basic law that, in case of uniform distributed loads, the 
bending forces are proportional with the span to the power of two remains valid. But also in this case one should carefully look at the costs generated in each step. Pre-stressed hollow core floors have several advantages: reduction of weight, optimal use of concrete for resisting bending forces, high quality concrete based on production in a carefully controlled environment, etc.

Also in this case a large fraction of the costs are independent of the size of the element. Another part will increase with the span. For bigger crosssections with more reinforcement the slope of this cost-in-function-of-span-line will be steeper. Again the cost per $\mathrm{m}^{2}$ floor will follow a downwards-sloping hyperbolic curve in function of the span:

Cost per element $=$ Fixed cost per element $+(\operatorname{span} *$ a) With $\mathrm{a}=$ constant for given section

Cost per $\mathrm{m}^{2}=($ Fixed cost $/($ span * width $))+(\mathrm{a} /$ width $)$

For uniform loads all producers of those prestressed floor elements provide "load-span" charts.

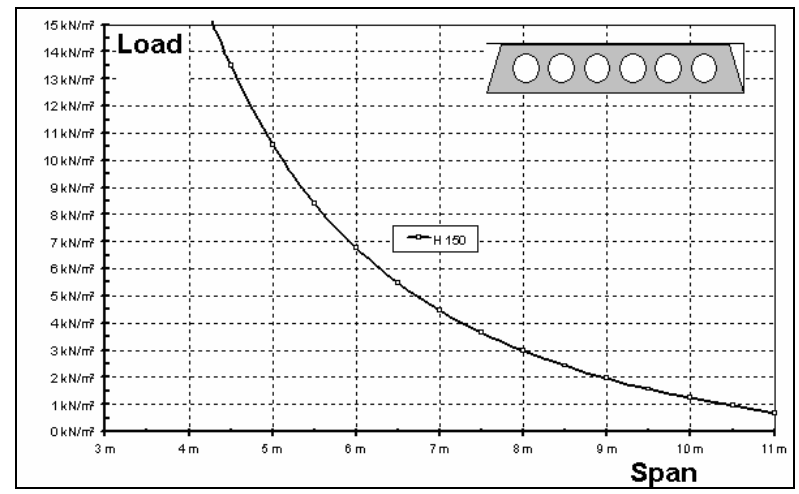

Figure 3. Load to span chart for a single floor type

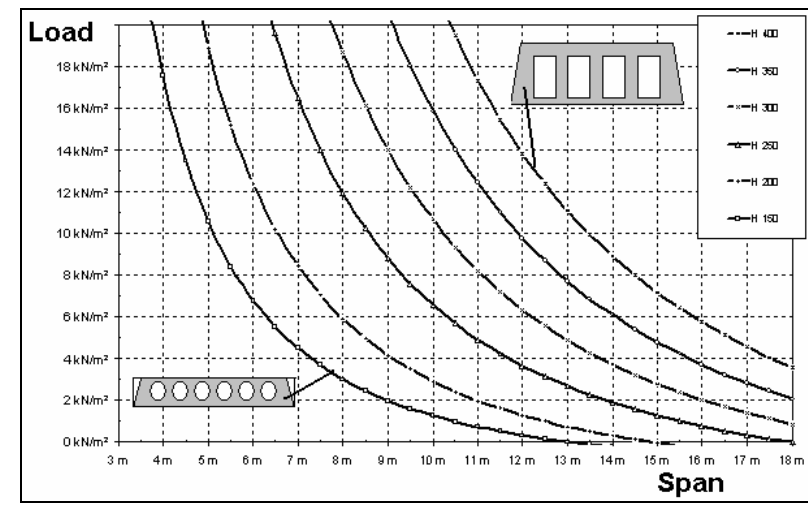

Figure 4. Load to span chart for a family of floors

Those graphs allow designers to select for a given load the appropriate cross section. This graphical tool can be combined with the cost graph per $\mathrm{m}^{2}$. When the span is increased for short spans the costs are high (effect of large amount of fixed costs per element) and will decrease hyperbolically up to the limit of the applicability of the floor element; at that point there is a sudden upwards jump to the next higher hyperbolic curve of the element with higher performance; This curve will be followed again until the limits of applicability of this crosssection; etc... The resulting "saw-tooth"-curve will have in general a relative steep downward sloop for short spans; an almost horizontal part for medium spans and a slow increase (due to jumping to more resisting elements) for longer spans.

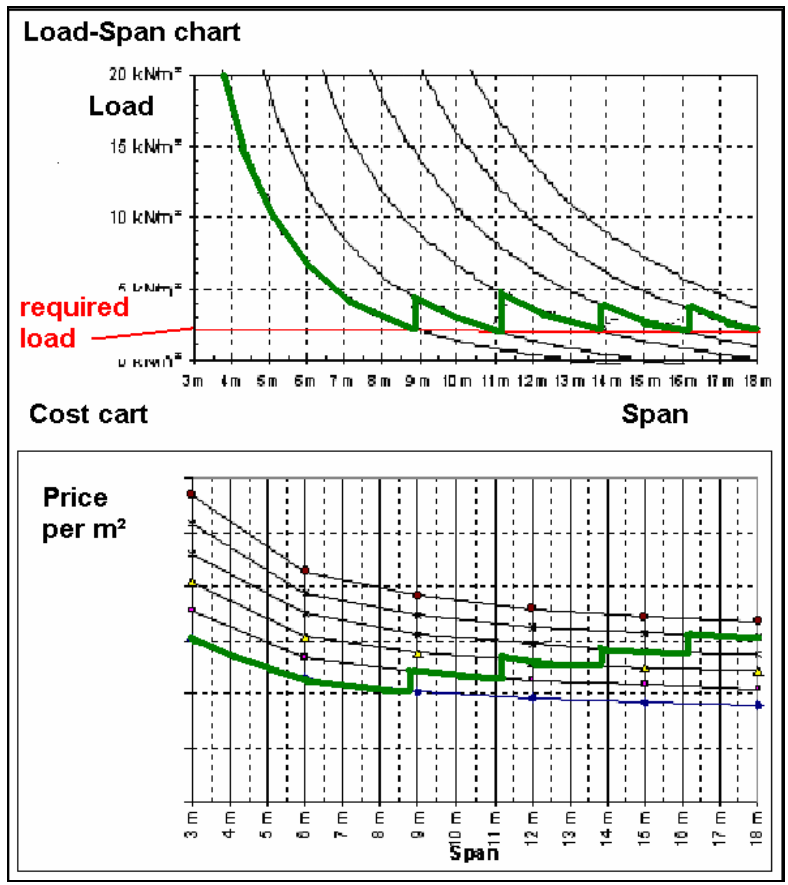

Figure 5. 'Load to span' chart combined with cost chart

This means that, compared to a design wit a lot of short spans, longer spans may almost not increase costs but create much more possibilities for adaptations to future needs. [De Troyer, Naert]

\section{INCLUDING COST IN USE}

One should not only look at the construction costs, but at the costs over the whole lifetime of the "support". How adaptable "supports" will be depends on many factors like access, distance to the facades, location of equipment, ... but for sure also on the size of the span. Larger spans will allow arranging spaces in different ways. Quantifying this in general is very difficult: small rooms designed to fit the original brief may be less appropriate if the family or organisation grows, if the way of living or working changes, if the property is sold to new users etc. 
In this text only a simple model will be elaborated considering following factors:

- Basic investment

- Major adaptation costs

- End value of support

- Rental revenue

The return on investment (sum of the present values over the whole lifetime divided by the basic investment) will be compared for two cases: an adaptable "support" (subscript A) and a not adaptable "support" (subscript N). Numeric values used for the basic simulation are mentioned between square brackets.

General parameters are:

$i=$ general inflation rate (is also growth rate of rents) $[2 \%]$

$r=$ interest rate for present value calculations [5\%]

$g=$ growth rate of construction costs; this is used for the evolution of the costs of major adaptation works and for the theoretical construction cost of the support at the end of the considered period. This reconstruction cost will affect the end value of the support [3\%]

$n=$ number of years considered in the simulation; at the end of this period the support is sold or demolished [60 years]

- Basic investment

The symbol $f$ is used as the mark-up value for a more flexible support. Investment cost are represented by the symbol $I$.

$$
I_{A}=f^{*} I_{N}
$$

\section{- Major adaptations}

For the non-adaptable "support" no adaptations are considered. For the other "support" adaptation costs are expressed as a percentage ( $a$ ) of the initial investment. In the simple version presented here the period in between adaptations $(p)$ is constant and the lifetime is a multiple of this period.

$$
\sum_{t=p}^{t=(n-p)} P V\left[A_{t}\right]=\sum_{t=p}^{t=(n-p)} a^{*} f * I_{N}\left(\frac{1+g}{1+r}\right)^{t}
$$

- $\quad$ End value of support

At the end of the lifetime two possibilities are considered: (1) the "support" has still a certain value or (2) the "support" has to be demolished. In the first case this value is estimated as a fraction (e) of the investment cost adapted for the growth of construction cost. In the second case the demolition cost (to be paid by the owner or to be considered as a correction of the selling value of the land) is also estimated as a (negative) fraction (e) of the investment cost adapted for the growth of construction cost. So the same mathematical formula can be used.

$$
P V\left[E_{n}\right]=e^{*} I\left(\frac{1+g}{1+r}\right)^{n}
$$

- Rental revenue

Annual hire is estimated as a fraction $(h)$ of the initial investment growing each year with general inflation. In the case of a non-adaptable "support" the fact that, year after year, the construction is less suited to the evolving needs, is included in the simulation by introducing a depreciation factor $(d)$.

$$
\sum_{t=1}^{t=n} P V\left[H_{t}\right]=\sum_{t=1}^{t=n} h I\left(\frac{(1+i)(1+d)}{(1+r)}\right)^{t}
$$

Parameters used for the basic simulation are summarised in table 1 .

Table 1: overview of parameters for basic case

\begin{tabular}{|l|c|c|}
\cline { 2 - 3 } \multicolumn{1}{c|}{} & Adaptable & $\begin{array}{c}\text { Non } \\
\text { adaptable }\end{array}$ \\
\hline Investment mark-up $(f)$ & $20 \%$ & $0 \%$ \\
\hline Adaptation costs $(a)$ & $15 \%$ & $0 \%$ \\
\hline Adaptation frequency $(p)$ & 15 years & n.a. \\
\hline End value percentage $(e)$ & $40 \%$ & $-5 \%$ \\
\hline Hire percentage $(h)$ & $8 \%$ & $8 \%$ \\
\hline Annual depreciation $(d)$ & $0 \%$ & $0.5 \%$ \\
\hline
\end{tabular}

The "present values" of all the flows for this basic case are represented in Figure 6.

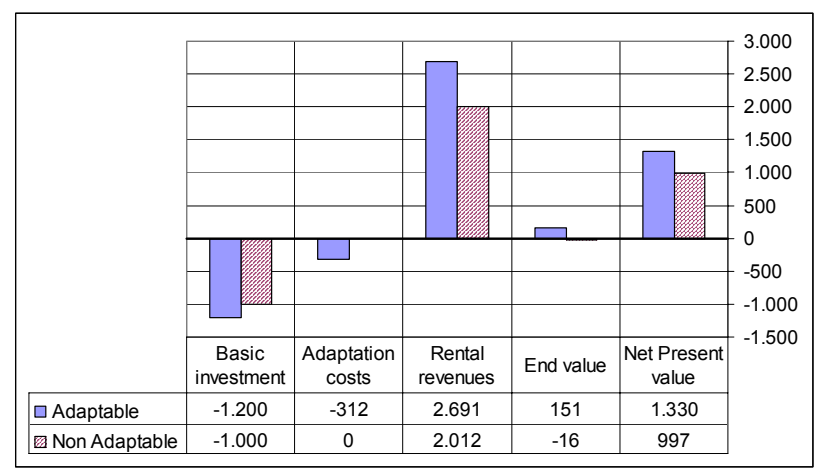

Figure 6. Present value of all the flows

In this case for the adaptable type the basic investment and the adaptation costs are higher, but the revenues as well. The end value expressed in present worth is not so important. The NPV of the adaptable "support" is higher but in order to compare with an alternative with a smaller basic 
investment it is better to calculate the NPV per unit of capital invested. An overview for the adaptable type of the PV's of the flows leading to this result can be found in Figure 7.

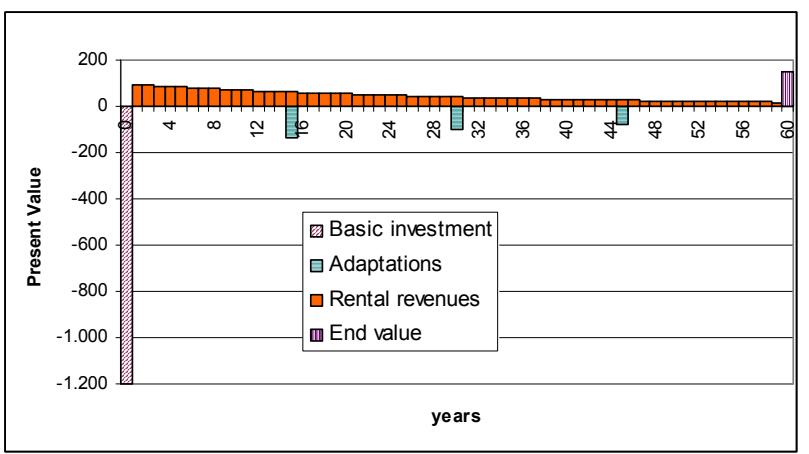

Figure 7. Present value of the flows represented at the moment they occur

The importance in present value of the adaptation works and of the end value is clear in a glance. An image showing how over the years the investment is compensated, is clearly pictured by a graph showing the sum of all the present values up to a given year (Fig 8).

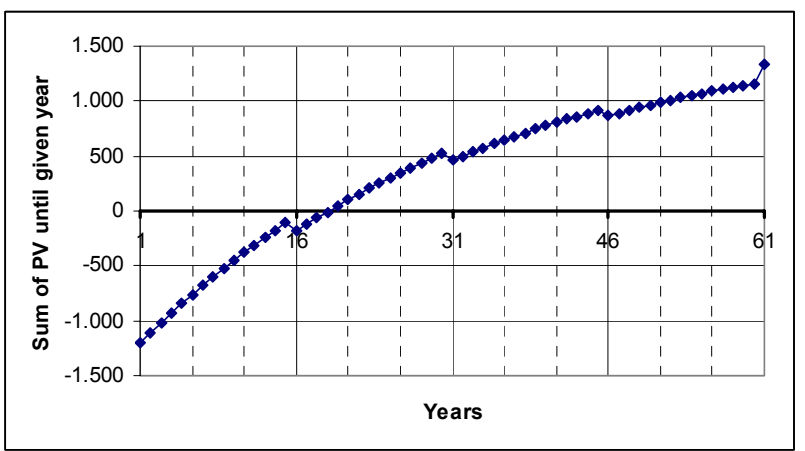

Figure 8. Sum of present values of the flows up to a given year

The first flow is the basic investment $(-1.200)$. The present values of the rental revenues are decreasing over time (Figure 6) so the curve of the sum of present values up to a given year is upwards sloping and the sloop is less and less steep year after year. In addition to that the graph is visualising the major adaptation works (= the downwards step every 15 years) and the positive end value in this case (= upwards jump at the end of the considered life time). In this case it takes 19 years before the investment is paid-back.

In order to compare with the non adaptable solution that requires a less important basic investment the "sum of the present value of all the flows up to a given year" is divided by the "absolute value of the basic investment". This is represented in Figure 9.

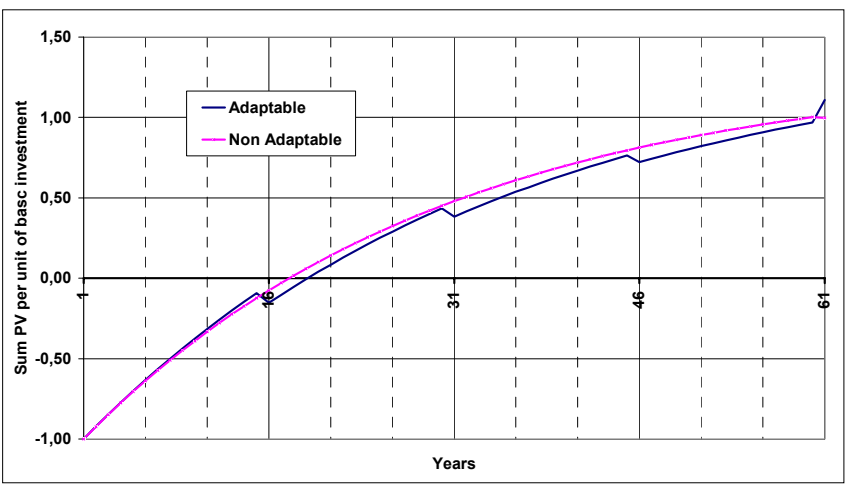

Figure 9. Sum of present values of the flows up to a given year per unit of capital invested

Those curves always start from minus one. Since in this basic case the estimated hire is twice $8 \%$ of the basic investment the revenues in the beginning are practically the same. The rental revenue for the non-adaptable type is slowly decreasing $(-0,5 \%$ a year). As a consequence the sloop is less steep compared to the rental revenues of the adaptable type. In the case of the adaptable type, however, the downward steps (due to adaptation costs) keep the curve below the curve of the non-adaptable case. The end value and end cost will invert the positions.

The first aim of this simple model is to present a way of analysing and representing the problem. This is a prerequisite before starting the discussion with actors involved. The next step is to analyse how sensitive the results are for certain parameters.

In table 2 all parameters are the same as in the basic case except the adaptation costs expressed as a percentage of the basis investment $(a)$ and the depreciation of the rental revenue $(d)$. This percentage indicates how the rental revenues will reduce year by year compared to a growth with general inflation. If inflation $(i)$ is $2 \%$ and this depreciation $(d)$ is also $2 \%$ the nominal rent will practically be constant: $(1+2 \%) *(1-2 \%)-1=-0.04 \%$.

The "adaptable" case can be compared to the "nonadaptable" by calculating "NPV/Basic investment" for the two cases and divide the value for the "adaptable" by the one for the "non-adaptable". In the basic case ( $a=15 \%$ and $e=-0.5 \%)$ we obtain: 


$$
\begin{aligned}
& \frac{N P V_{A}}{\left|I_{A}\right|}=\frac{1.330}{1.200}=1.11 \\
& \frac{N P V_{N}}{\left|I_{N}\right|}=\frac{997}{1.000}=1.00
\end{aligned}
$$

The ratio of the two is 1.11 as shown in table 2 .

\begin{tabular}{|c|c|c|c|c|c|c|c|}
\hline & & \multicolumn{6}{|c|}{ Annual depreciation $(d)$} \\
\hline & & $0,0 \%$ & $-0,5 \%$ & $-1,0 \%$ & $-1,5 \%$ & $-2,0 \%$ & $-2,5 \%$ \\
\hline & $5 \%$ & 1,05 & 1,29 & 1,60 & 2,03 & 2,63 & 3,53 \\
\hline \multirow{5}{*}{$\begin{array}{l}0 \\
0 \\
0 \\
0 \\
0 \\
.0 \\
0 \\
0 \\
0 \\
0\end{array}$} & $10 \%$ & 0,97 & 1,20 & 1,49 & 1,89 & 2,45 & 3,30 \\
\hline & $15 \%$ & 0,90 & 1,11 & 1,38 & 1,75 & 2,27 & 3,06 \\
\hline & $20 \%$ & 0,83 & 1,03 & 1,28 & 1,62 & 2,09 & 2,82 \\
\hline & $25 \%$ & 0,76 & 0,94 & 1,17 & 1,48 & 1,92 & 2,58 \\
\hline & $30 \%$ & 0,69 & 0,85 & 1,06 & 1,34 & 1,74 & 2,34 \\
\hline
\end{tabular}

Table 2: Sensitivity analysis for " $e$ " and " $d$ "

The advantage of the "adaptable type":

- will be reduced if the adaptation costs will increase and

- will increase if the non-adaptability will be reflected in stronger reduction of the rents.

Important questions that can be simulated with the model are:

- How important is the estimation of the additional basic cost of the investment $(f)$ ?

- What is the effect if the additional investment in the adaptable type is not reflected in higher rents from the beginning, but the rents are equal to the rents of the "non-adaptable" type?

- Can the rents after each major adaptation be increased? How much? What is the effect upon profitability?

- Can an important tax on demolition or waste disposal at the end of the lifetime of the nonadaptable type change the picture drastically?

The simulations make it evident that feedback of cost information from organisations in charge of running real estate projects and from organisations active on the rental market is essential for taking the right decisions in the early design phases.

Again a prerequisite is that cost information is available within the organisation and that contractual arrangements can be set up in order to come to a win-win situation: a better environment for the end user and higher profits other actors.

\section{CONCLUSIONS}

The separation in the construction sector between design, production, construction, use and maintenance is inherited from a slowly evolving area in the past. Optimisation is only possible if information is exchanged between different actors. Basic requirements are that the information is available within each organisation. On top of that arrangements have to be elaborated so that partners can benefit from making valuable information available for others: win-win situation. This principle is illustrated with two examples: information on production cost of prefabricated concrete elements and information on financial benefits of more adaptable "supports".

\section{REFERENCES}

[Habraken] Habraken, John, Supports: an Alternate to Mass Housing, (Edited by Jonathan Teicher, Reprint of the 1972 English edition; first published in Duch: De Dragers en de Mensen. Het einde van de massawaoningbouw. Amsterdam: Scheltema en Holkema, 1962), U.K., Urban International Press, , 1999.

[Innes and Mitchell] Innes, J., Mitchell, F., Activity based costing: a review with case studies, London, Chartered institute of management accountants, 1996

[Roztocki] Narcyz Roztocki, Introduction to Activity Based Costing (ABC) (dd 11/6/2003) http://www.pitt.edu/ roztocki/abc/abctutor/

[De Troyer] De Troyer, F., 'System building' or 'Industrialised building': A review of approaches and a vision for the future (p. 197-226) in: SARJA, A., (editor) Open and Industrialised Building, London, E \& FN Spon, 1998

[De Troyer, Naert] De Troyer, F., Naert, N. Ontwerpgids-Bouwen met prefab Deel 4: Stramienmaat: overspanning en herindeelbaarheid Brussel, FEBELCEM - FeBe, 2002 